\title{
Electromagnetic Processing during Directional Solidification of Particle Strengthened Aluminum Alloys for Additive Manufacturing
}

\author{
Imants Kaldre *, Mikus Milgravis, Andris Bojarevics and Toms Beinerts
}

Citation: Kaldre, I.; Milgravis, M.; Bojarevics, A.; Beinerts, T. Electromagnetic Processing during Directional Solidification of Particle Strengthened Aluminum Alloys for Additive Manufacturing. 2021, 3, x. https://doi.org/10.3390/xxxxx

Published: 22 February 2021

Publisher's Note: MDPI stays neutral with regard to jurisdictional claims in published maps and institutional affiliations.

Copyright: (c) 2021 by the authors. Submitted for possible open access publication under the terms and conditions of the Creative Commons Attribution (CC BY) license (http://creativecommons.org/licenses/by/4.0/).

\author{
University of Latvia, Institute of Physics, Jelgavas street 3, Riga LV-1004, Latvia \\ * Correspondence: imants.kaldre@lu.lv
}

\begin{abstract}
Rise of metal additive manufacturing technology has increased the demand for high performance alloys such as metal matrix composites (MMC). Metallurgical production of MMC remains a challenge. The nano-powder of dielectric particles does not mix well into the liquid metal because of several reasons. On a macroscopic level, the powder is rejected by the molten metal through buoyancy and surface tension forces. On a microscopic level, the particles are held together by Van der Waals forces forming particle agglomerates. Our research strategy is to address these issues separately in two steps. We are investigating electromagnetically assisted MMC casting method for production of particle strengthened directionally solidified aluminum alloys. In the first step, nanoparticles are mixed into melt while it is in a semi-solid state by efficient permanent magnet stirrers. Then the alloy is subjected to ultrasound treatment for fine particle dispersion. Semi-continuous casting of MMC is used to obtain material for additive manufacturing process. Material is casted in 6-20 mm rod by direct chill casting method, which can be made into wire with the application in wire-feed additive manufacturing. We investigate the possibility to improve $\mathrm{Al}$ alloy $\mathrm{SiC}$ composite material properties by applying electromagnetic interaction during solidification. Electric current and moderate static magnetic field (0.1-0.5 T) creates melt convection in mushy zone. Such interaction enhances heat and mass transfer near the solidification interface and hinders the reagglomeration of the added particles.
\end{abstract}

Keywords: Aluminum alloys; metal matrix composites; directional solidification

\section{Introduction}

Aluminum alloys are one on the perspective materials used for additive manufacturing. Aluminum is perspective because it has low melting temperature and lots of different alloys with fine-tuned properties for specific applications. There are several additive manufacturing methods how aluminum parts are made. Most common are additive manufacturing from powder [1]. The problem is that for successful additive manufacturing aluminum powder should be spherical particles with narrow size distribution and isotropic microstructure. Other alternative method is additive manufacturing using wire as starting material. This process is similar like MIG (metal inert gas) process. Powder additive manufacturing is less efficient, because of large material losses and slower speed; however, it is possible to achieve better quality and printing of more complex geometry is possible.

Electromagnetic methods for improved solidification process are one of the ways how to decrease grain size and improve homogeneity of the aluminum materials. Electromagnetic force near the solidification interface modifies the heat and mass transfer. To investigate this process usually directional solidification is used. 
Experimental setup is designed to investigate electromagnetic interaction on the solidification interface. Principles of direct chill casting of aluminum is explained in our previous article [2]. Static magnetic field of $0.4 \mathrm{~T}$ is provided by $\mathrm{NdFeB}$ permanent magnet assembly placed around the solidification zone. Aluminum A360 is induction melted in the top crucible and pressure casted in boron nitride tube. At the end of the tube water jet removes most of the heat. Solidification interface is located at the middle height of the BN tube. This ensures that from solidification interface heat is evacuated only in axial direction.

If electric current is applied parallel to the magnetic field, then Lorentz force appears at the solidification interface. In such configuration Lorentz force drives small scale melt rotation around each individual dendrite [3].

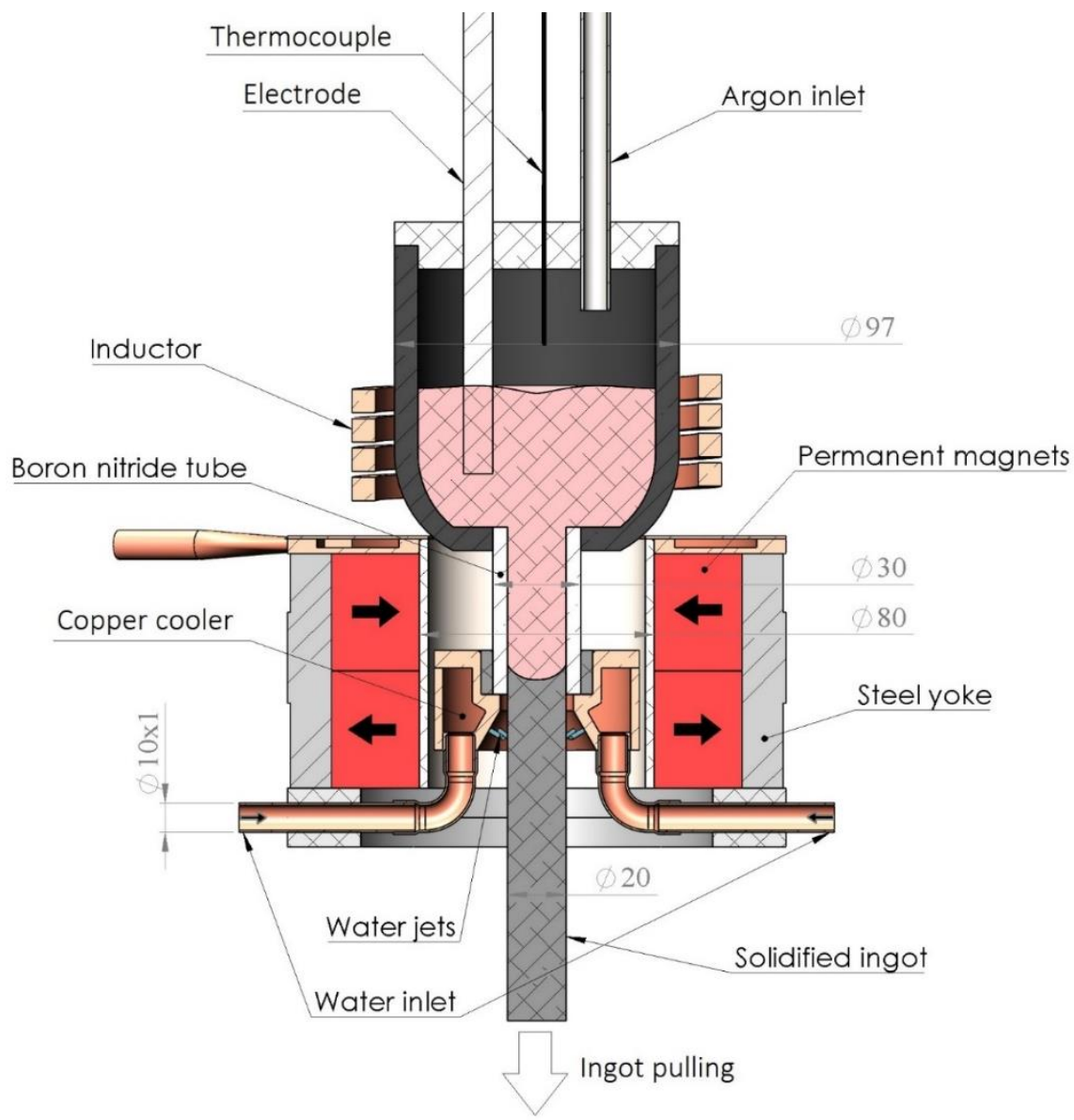

Figure 1. Directional solidification experiment schematics used in these experiments.

\section{Results and discussion}

We conducted series of experiments using our experimental setup. Direction solidification with direct chill casting of A360 aluminum were done with solidification velocity of $2 \mathrm{~mm} / \mathrm{s}$. Primary dendrite size in our experiments is around $50 \mu \mathrm{m} \mathrm{[4],} \mathrm{which} \mathrm{agrees}$ well with observations from our experiments.

Temperature gradient at the solidification interface is $20 \mathrm{~K} / \mathrm{mm}$, which leads to mushy zone thickness of several millimeters [5]. Experimental results are summarized in Fig.2 showing both transverse and longitudinal cross sections of the crystallized aluminum. Experimental results demonstrate that solidification without electromagnetic fields leads to longitudinal microstructure, which can be seen in Fig.2(d). Applied static magnetic field causes this longitudinal structure to disappear (Fig2(e). Such shift is columnar to equiaxed grain structure transition due to electromagnetic effect is known and reported 
in several scientific works. If electric current is injected parallel to magnetic field, significant small-scale melt convection takes place around the primary dendrites. This leads to radically increased heat transfer between solid and liquid phases. This results in fine grained structure formation and lots of eutectic phase pockets.
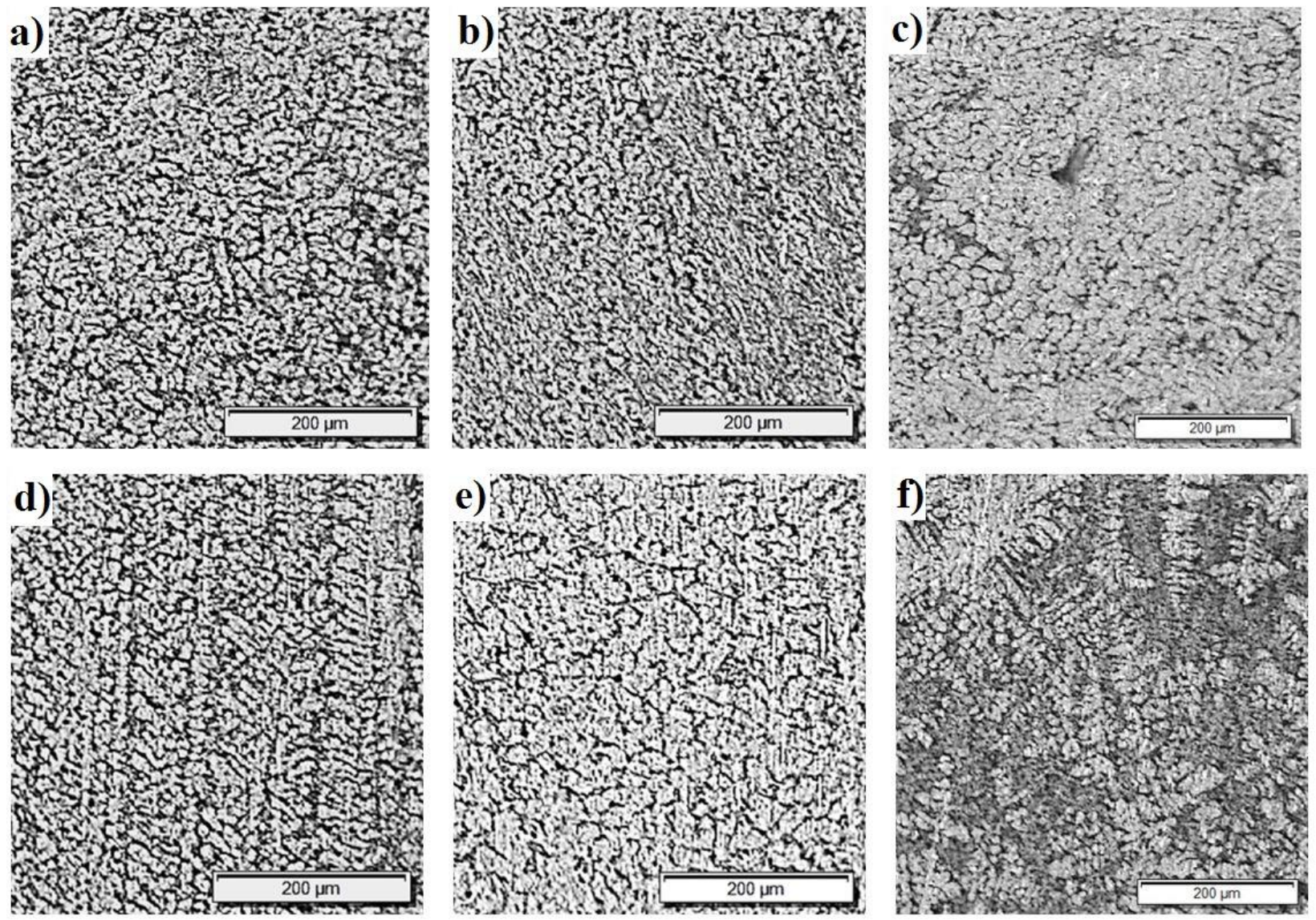

Figure 2. Directionally solidified A360 aluminium with solidification velocity of $2 \mathrm{~mm} / \mathrm{s}$. a,d) reference; $b, e) B=0.4 T ; c, f) B=0.4 T, I=157$ A.

\section{Conclusion}

This work demonstrates that solidification microstructure and impurity distribution in aluminum alloys can be modified by applied electromagnetic interactions. Applied magnetic field and electric current modifies columnar to equiaxed transition and refines grains, leading to more isotropic structure of directionally solidified A360 aluminum. As a continuation of this work it is planned to develop this method for electromagnetically improved Al alloy and Al based metal matrix composites. Aim is to produce wire for additive manufacturing by directional solidification.

Acknowledgement: This research is supported by ERDF project "Electromagnetic technology with nano-particle reinforced light alloy crystallization process for 3D additive manufacturing applications" (No. 1.1.1.1/19/A/080)

Imants Kaldre work is supported by Postdoctoral research grant « Electromagnetic methods for metal matric nano-composite production » No. 1.1.1.2/VIAA/2/18/264

\section{References}

1. Nesma T. Aboulkhair, Marco Simonelli, Luke Parry, Ian Ashcroft, Christopher Tuck, Richard Hague, 3D printing of Aluminium alloys: Additive Manufacturing of Aluminium alloys using selective laser melting, Progress in Materials Science, Volume 106, 2019, 100578

2. Andris Bojarevičs, Imants Kaldre, Mikus Milgrāvis and Toms Beinerts,2018 IOP Conf. Ser.: Mater. Sci. Eng. 355012011 
3. I. Kaldre, A.Bojarevics, Y.Fautrelle, J.Etay, L.Buligins. CURRENT AND MAGNETIC FIELD INTERACTION INFLUENCE ON LIQUID PHASE CONVECTION. MAGNETOHYDRODYNAMICS Vol. 48 (2012), No. 2, pp. $43-49$

4. Ostad Shabani, Mohsen \& Mazahery, Ali \& Bahmani, Ahmad \& Davami, P. (2012). Solidification of A356 Al alloy: Experimental study and modeling. Kovove Materialy. 10.4149/km_2011_4_253.

5. W. Kurz, D.J. Fisher. Fundamentals of Solidification 4th Edition. CRC Press; 4th edition (June 1, 1998) 